\title{
PELO AVESSO: A Leitura e o Leitor
}

Eliana Yunes*

\section{Nas trapaças do leitor...}

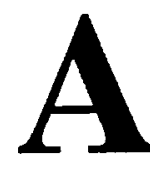

relação entre ler e prazer tem sido, nos últimos anos, valorizada, depois de décadas em que se falou cm criar o hábito de leitura, como se bastasse automatizar um gesto e executá-lo seın maior atenção, como quem, dirigindo um carro, aperta pedais e passa marchas.

A questão, no entanto, é de outra ordem. Prazer, nos ensina a psicanálise, ć un estado de satisfação do desejo, em que todo individuo encontra o bem-estar, ainda que temporário, ainda que efêmero. A tendència humana, entretanto, é buscar repetir estas experiências em compensação pelas situaçōes repressivas, isto é, em negação ao que separa, restringe, reduz.

O ato de ler é um ato da sensibilidade e da inteligência, de comprecnsão e de comunhão com o mundo; lendo, expandimos o estar no mundo, alcançamos esferas do conhecimento antes não experimentadas e, no dizer de Aristóteles, nos comovemos catarticamente e ampliamos a condição humana. Esta sensação de plenitude, iluminante, ainda que dolorosa $e$ aguda tem sido a constante que o discurso artístico proporciona. Diante de um quadro, de uma música, de um texto, o mundo inteiro, que não cabe no relance do olhar, se condensa $e$ aprofunda em nós um sentimento que abarca a totalidade, como se, pela parte que tocamos, pudéssemos entrever o não-visto e adivinhar o que, de fato, não experimentamos.

Pontificia Universidade Católica do Rio de Janciro (PUC-RJ) e PROLER: Programa Nacional de Incentivo à Leitura. 
O prazer é lambém um longo aprendizado, embora esteja presente desde sempre, nos ensina Freud, na pulsāo de vida. A manifestaçāo do prazer precisa ser cultivada, atentamente acompanhada, para que se possa descobrir as condições de sua produção.

Com a leitura não acontece de modo diverso. Há que se perguntar pelo que é ler, como ler, para usufruir de seu prazer. A prática leitora nas sociedades contemporâneas não corresponde, via de regra, senão ao uso estrito imposto pela sociedade de massas. Lemos anúncios, quadros de indicação óbvia, como "saida", "é proibido fumar" e mesmo assim saimos pela entrada e fumamos onde não é permitido. Uma advertência menos corrente não é sequer assimilada pelo olhar que decifra as letras: "aguarde em fila única" e lá estamos nos atropelando em balcōes a necessitar de cordas que nos encurralem para proceder conforme $a$ indicação.

Na sociedade brasileira, uma das metades não lê porque não sabe, a outra porque não quer. Por que então insistimos na escola? Pelo diploma, pelo cumprimento formal de um rito iniciático ao universo da produção? Repito, vamos à escola "aprender a ler" e saímos de lá detestando tudo que se relacione com ela: estudo, pesquisa, redação, etc.

Evidente que, além do processo de iniciação, - nisto os construtivistas têm razão - em que a palavra escrita não é fragmento, mas corresponde à mesma totalidade da linguagem dominada oralmente (ainda que só por hipótese, a principio), a leitura deve constituir-se em um recurso para se alcançar o mundo que não temos, não conhecemos e sequer imaginamos.

Ler significa descortinar, mudar de horizontes, interagir com o real, interpretá-lo, compreendê-lo e decidir sobre ele. Desde o início a leitura deve contar com o leitor, sua contribuição ao texto, sua observação ao contexto, sua percepção do entorno. $O$ prazer de ler é também uma descoberta.

Será, contudo, muito difícil descobri-lo se não há condições explícitas para esta intimidade. $O$ teórico francês Foucambert tem advertido que a oferta de leitura para além dos out doors deve ser considerada seriamente pelos administradores sociais; que a valorização da palavra escrita deve estar presente para os cidadāos em espaços sociais diversos, dos parques aos muscus, incluindo a TV c os novos mídia.

Em meio à grave crise social em que nos debatemos há décadas, com uma população empobrecida, desperdiçada, descrente, sem perspectivas de futuro melhor, testemunha da vantagem e impunidade dos oportunistas, a educação tem-se revelado inócua, e, no bojo dela, o papel da leitura começa agora a ter que se explicar.

Malgrado isto, é justamente a afirmação de uma consciência crítica que possa articular situações, opiniões, fatos, que nos dará condição de intervir, 
optar, decidir sobre o universo que nos toca. Neste caso a informação é definitiva, se aprendemos como usá-la. Só então ela se transforma em conhecimento e saber. Esta é a mais cara moeda do século: quem está informado pode com mais rapidez e clareza fazer escolhas. Descobrir o serviço que a leitura presta, a capacidade que cla tem de fortalccer a cidadania, é um começo.

Ler para quê? Para as provas? Para o vestibular? Para o concurso? Ler para viver. Ler a vida. Ler para ampliar as perspectivas, para associar idéias, para reinventar o mundo, a partir da condição pessoal. De nada adianta "passar de ano", obter um certificado, se não há mudança qualitativa de vida. Sem dúvida, a leitura por si só, não resolve os problemas sociais e/ou individuais, mas ter opções, compreender as situações é menos amargo que ser levado, sem dominio ao que se passa em torno. O conhecimento de outras vidas, de outros tempos, de outras histórias, de outras culturas se oferece como contraponto, e as dimensões de uma tragédia grega fazem eco cm ocasiōes cotidianas de um cidadão comum: quantas Medćias, quantos Penitones temos conhecido? Se é possivel ver a ancestralidade de certas histórias, nos sentiremos como assinala Frank Smith, menos autômatos, menos solitários.

Há, portanto, um prazer na informação obtida, há uma sensação de mundo mais amplo que a leitura pode trazer, mesmo às margens do século XXI, numa sociedade eletrônica onde o visual parece substituir o verbal, ganhando com a simultaneidade de sinais um maior impacto que a seqüencia linear das palavras. Estas, contudo, não têm transparência absoluta, não são o que parecem ser nem são descartáveis em seu valor de uso: ninguém lè, hoje, Iracema, de Alencar, apenas pelo seu significado no século XIX, e sua leitura, agora, redimensiona o romance aos olhos de novos leitores do século XX. As palavras flutuam mesmo quando as queremos precisas porque, tanto quanto a razão lógica, elas nascem do imaginário humano.

Deste modo, dentro e fora da escola, crianças e adultos, precisamos reaprender a ler, a reinventar a leitura. $E$ o começo é perceber que não lemos palavras, lemos sequiências onde as palavras se comunicam, se negam, se contradizem c nos surpreendem: espreitar suas relações, observar suas ambigüidades, pode nos proporcionar um espaço mais rico de conhecimento: "claro enigma", nos dizia o poeta Drummond. Partilhar segredos, percorrer mistćrios, é tentador. Viver a aventura da palavra é viajar pelo tempo/espaço. O relato oral, as narrativas antigas sustentaram a história do mundo e das civilizações até que a escrita, prometida como cura para o esquecimento, quis-nos garantir a memória fixa, e tomou-se veneno para a experiência humana, segundo o diálogo de Platão em Phedro. Sabedores disto, mesmo ortodoxa, mesmo sagrada, a palavra é múltipla e vária: “que é a verdade?", perguntava o inquisidor romano diante do Nazareno, temendo sua resposta. 
Ler é, pois, interrogar as palavras, duvidar delas, ampliá-las. Deste contato, desta troca, nasce o prazer de conhecer, de imaginar, de inventar a vida. O mundo é representação de linguagem, hoje sabemos. Nada há que esteja fora das palavras, e o mundo real tem tantas formas quantos discursos há. Neste calcidoscópio de perspectivas, o horizonte se rasga, vivemos muitas vidas e conhecemos melhor a história cotidiana. Nasce do prazer de ouvir - as histórias da primeira infância nos povoam de densidades e mistérios para sempre - até que possamos nós mesmos brincar com as palavras, jogar seu jogo pesado, matar e fazer viver com elas.

Se o professor, o pai, o bibliotecário, o mediador inicial enfim, deixam escapar esta chance de apresentar o sabor das palavras, o gosto do saber vai desaparecendo paulatinamente, até que nos isolamos num mediocre vocabulário cotidiano, lemos só o já lido, fícamos cegos diante da luz. O aprendizado da leitura técnica, psicológica e filosoficamente é uma tomada de posse do mundo nesta civilização da escrita. Em outros tempos, era o verbo da oralidade; hoje, o da imagem, mas sempre é o verbo: lê-lo, aproximá-lo, é aproximar-se de uma condição (in)suspeita, onde, dirigidos que somos por ele, lutamos para dirigi-lo e experimentar um novo prazer. "Lutar com as palavras é luta vã", provocou o poeta que, com sua obra, nos provou o contrário.

A questão, no entanto, não se limita a consideraçōes de ordem filosófica. Com freqüència, em nosso país ao menos, há um abismo entre o pensar e o fazer, como se a inscrção do pesquisador na prática, conspurcasse o seu livre-pensar. O que sustenta o desenvolvimento das teorias é a análise das práticas.

Foi, pois, obscrvando a relação inicial das crianças com a escrita c a leitura, que em 1972, supervisionando a escola básica de um colégio de grande prestigio no Rio de Janeiro descobri algumas faces de uma mesma questão e de quanto mais havia com cla relacionado. Primeira: crianças precisam desde pequenas de uma convivência gratificante com livros e histórias; por isso era indispensável a consolidação de uma biblioteca infantil com acervo atualizado, e fazê-las recuperar a experiência de ouvir contos. Segunda: rarissimos professores gostam de ler, e só como fiscais acompanham a hora de visita à biblioteca. Terceira: algumas vezes fazíamos projeções de histórias em slides, noutras a bibliotecária, ainda tímida, contava uma história e nas oportunidades seguintes os meninos, orientados por uma catalogação a cores na lombada, escolhiam os livros. Quarta: a biblioteca como espaço de “folga” e do puro lazer, só a princípio surtiu efeito. Era preciso percebê-la como lugar da curiosidade satisfeita, da pesquisa que, bem orientada, pode ser extremamente compensadora, aliviando a pressão dos trabalhos "em" casa. Quinta: professor não sabe e não gosta de pesquisar - era, pois, uma necessidade orientá-los para saírem de suas aulas padronizadas, carbonadas, literalmente, de uma para outra sala, nivelando 
turmas diferentes no ritmo do padrão único. Sexta: a leitura para o prazer de se divertir ou de estudar era uma experiência penosa para a maioria das crianças. Mas quem gostava de ler ao seu redor? Uma enquete feita entre os pais mostrava que liam as colunas sociais, esportivas e economicas (na faixa da média e alta burguesia). Os professores não tinham esta prática, os meios de comunicação não ajudavam.

Tentamos o círculo de leitura com os professores - adesão voluntária mas seria preciso fazer o mesmo com os pais. E obrigatoriamente mudar o tratamento da leitura na sala de aula e na biblioteca. Diante das perguntas por onde começar? o que ler? optei a principio, pela literatura oral, tema de todos. Por ai, descobri que a prática leitora pode ser sensivelmente ampliada se convivemos com histórias literárias de qualidade. E não é tão complicado, circunstanciados historicamente, dizer o que é literariamente bom: os recursos de linguagem no discurso literário desdobram a mimesis e a verossimilhança até perspectivas nunca dantes enfocadas. De um "causo" com foro de verdade a um enredo imaginário, entre unicómios e moças tecelãs, é possivel criar uma credibilidade que co-mova o ouvinte/leitor. Como um bumerangue, o lexto sai das mãos do autor, se distancia dele e do leitor, c numa curva imaginária longinqua redescobre o caminho de volta como que "pescado" pelo surpreendido leitor.

O mundo organizado se desorganiza, o mundo caótico ganha sentido, o fantástico é experimentado, a história ganha condiçōes de maravilhoso e o maravilhoso de verdade. Aqui e ali o mundo se explica. A brutalidade da vida nordestina é mais autêntica em Vidas Secas do velho Graciliano Ramos que cm tratados de antropólogos, cientistas sociais ou geólogos. A literatura desrcaliza e vivifica; desenfoca e aproxima; sintetiza e revela. A palavra instaura o mundo (no princípio era o Verbo): o leitor interagindo com o texto é co-autor e sente perpassá-lo a condição de criador. O literário, scm compromissos com a História, mostra seu avesso e as tramas do tecido (texto) aparente. Por isso, grandes ensaistas, pesquisadores, filósofos não prescindem da literatura ou da referência à arte: Freud, Foucault, Bachelard, Barthes, para falar apenas dos contemporâneos, entremearam com ela seus discursos de saber psicanalítico, fillosófico, semiológico.

De uma boa história ninguém escapa, atesta o “conto do vigário”. Sempre queremos ouvir mais uma, como o velho sultão Shaishar que, esquecendo a morte anunciada, redescobria a vida fluindo das narrativas de Sherazade. 


\section{Nas tramas da leitura, tecendo o leitor}

A iniciação à leitura para os que ainda dela conseguem se lembrar, tem um viés de aventura que atrai $\mathrm{c}$ amedronta, seduz $\mathrm{e}$ ameaça. No balanço desta ambivalência, a relação afetiva, boa ou má, pode imprimir contornos duradouros à experiência de ler.

Quem nos sentou nos joelhos ou debruçou-se sobre nosso livro e descortinou mundos com as palavras? Ou quem com garras e dentes de impaciência tirou nacos de nossa fantasia e fechou o mundo das idéias que se abriga no verbo?

A pedagogia da leitura na escola não tem logrado grandes êxitos na criação de leitores permanentes. Poder-se-ia discutir a alfabetização e suas metodologias, ou abordar a inadequação escrita entre a concepção de dominio do código gráfico - certamente são reflexões indispensáveis no conjunto destes estudos - mas isto não bastaria para explicar a rejeição da leitura dentro e fora da escola. E caberia ainda uma pergunta: em que medida a alfabetização não tem sido "descolada" da leitura em seu gozo especilico e manipulada como técnica apenas?

No entanto, é dramático hoje, o cfeito da ausência da leitura no meio escolar e social. Todas as disciplinas - todas - carecem do domínio da leitura para se desenvolver: das humanidades às ciências, das artes às matemáticas. Ler formas, símbolos, letras, signos, imagens significa prover, estabelecer uma relação entre eles c uma relação com eles, também nas diferentes instâncias da vida social.

O problema transborda da escola para a sociedade onde a prática da leitura é automatizada, limitando-se a letreiros, alguns avisos - ignorados imperceptivel ou deliberadamente - c, na rotina, passa sem ter maiores efeitos sobre a vida cotidiana. A leitura, que rasgaria horizontes, permitiria o sobrevôo, das circunstâncias e colocaria a informação a serviço da vida pessoal e social, se embota com o pragmatismo dos "deciframentos", onde a relação do leitor com o mundo se esteriliza, no assético processo de alcançar as essências mesmas do "que-o-autor-quis-dizer" apesar de que ele tenha dito de fato, algo.

Paradoxalmente esta é uma sociedade onde tudo é legível - os comportamentos, o traçado das vias públicas, as decisões políticas, os programas de televisão, o tom dos locutores de rádio, a violência do trânsito, a sujeira nas ruas, os noticiários comprometidos, a miséria sob os viadutos, os grafites indecifráveis sobre os muros, o abandono dos serviços públicos, as peças e filmes $\mathrm{em}$ cartaz, os últimos lançamentos de obras de auto-ajuda, o escrutinio nas academias, o salário do professor e do médico, o atendimento nas bibliotecas públicas, a ação da polícia e tudo o mais que se queira nomear. 
Num mundo que restringiu a prática da oralidade à passividade dos ouvintes/telespectadores: que se contentou com garranchos de uma assinatura como sinal de alfabetização; que transformou a comunicação em controle ideológico de massas e que traz na telemática a falácia da democratizaçāo dos serviços de primeiro mundo para a plebe; neste mundo, o conceito de leitura precisa ser revisto assim como suas práticas de iniciação e de reabsorção, pois assombra já aos paises industrializados e de população alfabetizada os estragos que esta ausência vem causando à minada prosperidade econômica.

O que seria preciso reconsiderar, reler neste percurso das práticas leitoras, para instaurar novas percepçöes do ato de ler e readmitir neste exercicio algo substantivo que interaja com o leitor potencial e promova a qualidade da vida social ?

Consideremos algumas linhas nesta trama de formação do leitor, jả que os pontos incisivos do processo, até então familiares aos iniciadores pelas concepçōes c métodos, pouco têm ajudado o leitor iniciante na conquista delinitiva desta prática.

\section{a. Mcmória}

O sujeito é um ser histórico, cuja inserção temporal também marca seu perfill. O tempo é uma categoria visceral na condição humana. É contra seu fluxo inexorável que a vida luta por permanccer. A riqueza deste embate não está na impossivel obtenção do presente eterno: à lincaridade do tempo o homem contrapõe o seu exercício da memória, arrancando simultaneidades.

Mas lembrar não é apenas evocar um conceito passado através de outro atual. A memória antes de ser um filme rebobinado à cena inicial que nos interesssa recuperar, elabora uma série de sensaçōes, sentimentos, percep̧̧ões e imagens para só então "construir-se" como um referente.

Numa evidente herança das formulaçōes psicanáliticas, a memória assim concebida não é uma reconstituição "pura" mas atravessada, às vezes imperceptivelmente e associada, inconscientemente a fenómenos aparentemente distantes daquele evento original. As associações elegem o que vai ser rememorado e resulta numa "criação" que só em parte corresponde ao dado.

O exercicio da memória nunca poderá efetivamente resgatar o fato tal como ele se deu em todas as suas injunçōes presentes, passadas e ...futuras. A memória fabula, condicionada pelos tipos de registro que se imprimiram em nosso inconsciente. Vem à tona mobilizada por elementos heterogêneos aparentemente, mas por um percurso em que a própria memória se contrói. 
O processo de descoberta e afirmação do eu, tem então como elemento constituinte fundamental a tomada de consciência da própria história, o entrelaçamento das memórias pessoais e sociais, o situar-se no tempo entre os homens. Este exercicio desencadeia a valorização do sujeito, desautomatiza o estar no mundo "como qualquer outro" e começa a conferir uma certa identidade a cada ser humano.

$\mathrm{O}$ ato de ler, na medida em que vem apelar ao receptor por sua participação, acaba provocando suas memórias e nelas, suas posturas, scus sonhos, suas opiniōes antes tão encobertas ou desconhecidas por ele próprio. $O$ ato de ler convoca ao exercício de pensar e neste, ao de se encontrar.

Pensar, pesar, evocar, rememorar as experiências iniciais e posteriores da leitura, por exemplo, são gestos que afetam o ato de ler e o impregnam das vivencias de cada um, dando-lhe a oportunidade, pouco a pouco, de conscientizar-se.

b. (Inter)subjetividade

Comecemos por uma das noções sobre a qual se arquitetou a tcoria do conhecimento. Sendo o sujeito aquele que detém uma experiência pessoal, individual, relativa a sua interioridade particular, pode-se valorizar a importância desta consciéncia de si mesmo no processo de conhecimento como um todo.

Contudo o homem não pode formar uma consciência unilateral de si mesmo, nem mesmo forjada, sem contato com o entorno ou a realidade da qual partilha. O sujeito, é verdade, elabora subjetivamente hipóteses sobre as coisas que perscruta, que observa. Reconhecendo nas coisas uma realidade, sabe, no entanto, que percebe dela alguns aspectos apenas e que, de todo modo, a idéia que dela forma vai ser a imagem pela qual a reconhece e identifica.

O conhecimento, malgrado os esforços de objetividade, está "contaminado" pelo recorte ou grade que a sensibilidade e o entendimento de cada um lhe conferc. $O$ objeto, por outro lado, já aparece aos olhos do sujeito comprometido pelas "idéias" e imagens que experiências suas anteriores the transferem.

Portanto, o ato de conhecer envolve inapelavelmente o sujeito com o objeto que pretende conhecer e o olhar que dirige sobre o mundo acaba sendo um foco sobre si mesmo.

$E$ isto não é tudo. Os sujeitos, porque não estāo isolados, formulam este conhecimento em sistemas de expressão e comunicação, as linguagens. Estas linguagens e a língua materna $\mathrm{em}$ particular trazem marcas do seu uso pelos falantes. Estas marcas - como, por exemplo, o lugar de onde uma palavra soa ou destoa em certo contex to - muitas vezes não são percebidas conscientemente 
e atravessam nosso discurso pessoal. Dito de outro modo: somos atravessados por uma permanente intersubjetividade, quer queiramos, quer não. Ela fala de nós e fala sobre "com quem andamos".

Então tomamos consciência de "nossa" linguagem, de linguagens outras e compreendemos que o conhecimento, o saber se dá num processo complexo de intercruzamentos permanente de vozes e que "nossa" palavra instaura uma visão do mundo sobre a realidade com marcas que a linguagem, de alguma forma, carrega como que cicatrizes.

\section{c. Inter(pret)ação}

A leitura não se constrói sobre o nada. Há algo que provoca o leitor, the interessa, lhe instiga um outro pensamento que lhe permite dar asas à imaginação.

Como um papagaio/pipa na mão de um menino, a leitura viaja sem se desprender de sua raiz: a raiz da leitura é o mesmo que a possibilita, uma relação entre a pipa e a mão, entre o texto e o leitor, que voa sem rotas determinadas $a$ priori.

O ato de ler, assim, carrega para um encontro intersubjetividades e memórias várias que se interpenetram e resultam na interpretação.

A problemática da interpretação é antiga e esteve comprometida com a explicação de textos enigmáticos como os religiosos. Neste caso, apontaria para a necessária "descoberta" do sentido oculto no sentido aparente. A mediação exigia, pois, um autor ou intérprete autorizado, o que conduzia a interpretação para o lugar do ideológico, isto é, dos valores aparentemente consensuais que dominavam tal sociedade.

Mas interpretação não é decorrência linear do que está codificado em linguagem, não é desocultamento do mistério do texto, mas do mistério do próprio leitor. Interpretar é um ato de leitura que associa o sujeito ao discurso que elabora e o explica enquanto se explica.

Modernamente, com o redimensionamento do conceito de sujeito, com a discussão do lugar da linguagem na teoria do conhecimento e com o fortalecimento da figura do leitor no processo da significação discursiva, a noção de interpretação também se altera.

As memórias de leitura e de vida, as intertextualidades, a dubiedade de suas intençōes, pelo menos, das intençōes do autor, as marcas do texto, a perspectiva comunicativa entre sujeitos, recuperam a dimensão interativa da ação humana e colocam a interpretação num processo permanentemente descentralizado. Isto não equivale ao vale-tudo dos "achismos", pois referências 
contextuais integram o universo do discurso e são indices que o leitor recolhe ou não, e arranja segundo seus próprios desejos e intenções.

\section{d. Fruição}

Entre a necessidade da informação para poder participar das decisões sociais e o movimento psíquico-físico que as emoções e a inteligência despertam em nós durante uma leitura, há contradições. Muitas vezes se tem repetido que ler deve (!? )ser um prazer e muitos presumem que o prazer se identifica com a catarse segundo a formulação aristotélica. Em parte, sim, pois é possivel a emoção de um ato mesmo não vivido, que demande novas percepções e investimentos para sua realização, ainda que imaginária.

No entanto, o efcito sobre o afetivo e o intelectivo na recepção de um texto não se mede pela comoção inicial ou pelas lágrimas derramadas. Ao contrário, o "in-sight" detonador do apenas intuido, entrevisto, desdobra-se de forma prolongada e duradoura em fruição. Este movimento expande o prazer de forma gradual e intensifica o desejo de maior intimidade e convivência com as imagens desencadeadoras deste bem-estar ou desta dor que não se esvai com o término do ato de ler.

A fruição decorre de uma percepção mista de necessidade e prazer, desliza sobre o tempo e não pesa sobre o leitor, na medida em que uma intimidade cada vez maior, uma inter-relação cada vez mais ágil se faz entre as leituras e os recortes de leitura produzidos por quem se coloca em interação com a obra.

Este envolvimento é acionado pela qualidade da própria obra, que desrealizando o mundo, isto é, apresenta-o em uma dimensão perspicaz, inédita, ao mesmo tempo em que convida seu leitor a adentrar neste espaço com seu imaginário. Dai talvez valha a pena assimilar com Barthes a diferença entre leitura de fruição e leitura de prazer. Esta permite o esgotamento rápido das sensaçōes; aquela permanece e interroga.

\section{e. Intertextualidade}

Neste périplo, experimentando os aspectos envolvidos na interação texto-leitor de que resulta a leitura como conhecimento do mundo, seja na dimensão da história, seja na ficção, há que se reconhecer que o verbo que estrutura o pensamento, não constitui a forma inevitável da concepção para sentimentos, razões e desrazões: o texto se estende sobre a página, sobre a tela, no ar, nas relações, nos desejos e busca a linguagem que possa melhor expres- 
sá-lo. Raramente, os sentidos e as "representações" do mundo se expressam numa única linguagem: são formas e cores e palavras (os títulos); são sons e palavras (as letras); são versos e ritmos (a musicalidade); são movimentos em imagens e sons; ć o gesto, o corpo, a voz, entremeando expressões que associam linguagens e recobram outras.

A memória ajuda a entretecer intertextualidades, o mundo sendo sempre um texto a se recompor por quem o lê e reescreve.

$\mathrm{Na}$ tentativa de realizar a comunicação, os homens passaram dos índices aos símbolos, aos sinais e os retomam assim como às imagens sem hierarquias de valor. $O$ exercicio da capacidade de dizer-se inventa linguagens, renova as artes e a ciência se beneficia do convivio com o imaginário.

O "texto" está no mundo e a leitura como a escrita o recortam enquanto discurso, deixa-se levar por eles, mas não se esgota nem à linguagem que lhe dá suporte. O amor, veja lá, é um texto que sonetos, filmes, fotos, danças, pesquisas não esgotam. Mas quem o "aprende", quem o vê, é o leitor do mundo, aquele que subitamente às vezes lhe dá forma peculiar.

\section{f. Escrita}

Ler é, pois, um ato de primeira instância no esboço da consciência de si mesmo e do outro e sua inscrição no mundo se dá como uma escrita, de vida. Do ato de ler decorre o ato de se escrever, de escrever a própria história e dos outros, de marcar a própria existência social com traços que podem, no entanto, guardar-se sob a forma das oralidades, tanto quanto ganhar volumes, cores e sinais.

A dimensão, pois, do ato de que se crê centralizado depois da alfabetização, está longe de ser reduzida às letras combinadas em códigos fonéticofonológicos, morfológicos e sintáticos. A leitura nāo é mero excrcício sobre a escrita dos outros, mas formulação lenta da própria escrita em relatos e ações.

Ler é inscrever-se no mundo como signo, entrar na cadeia significante, elaborar continuamente interpretações que dão sentido ao mundo, registrá-la com palavras, gestos, traços. Ler é significar e ao mesmo tempo tornar-se significante. A leitura é uma escrita de si mesmo, na relação interativa que dá sentido ao mundo. 


\section{RESUMO}

Este artigo discorre sobre a importância e necessidade da leitura, concebida enquanto interação com o mundo, enquanto descoberta e enquanto prazer. Apesar de seu valor, a sociedade brasileira relega a leitura a planos sempre secundários, encarando-a como uma experiência penosa. Na tentativa de compreender este divórcio e investigando o percurso das práticas leitoras, o texto considera alguns componentes do exercício da leitura: a memória, a intersubjetividade, a interpretação, a fruição, a intertextualidade e a escrita.

Palavras-chave: leitura, práticas leitoras, formação do leitor.

\section{RESUMEN}

Este articulo trata sobre la importancia y necesidad de la lectura concebida como interacción con el mundo, como descubrimiento y como placer. A pesar de su valor, la sociedad brasileña la relega siempre a un segundo plano, encarándola como una experiencia penosa. En el intento de comprender este divorcio e investigando el recorrido de las prácticas lectoras, el texto examina algunos componentes del ejercicio de la lectura: la memoria, la intersubjetividad, la interpretación, el deleite, la intertextualidad y la escritura. 